\title{
Survey of Cysticercus (Bladder Worm) in Meat Sold for Consumption in Bukuru, Plateau State Nigeria
}

\author{
Kaze, P.D. \\ Gam, K.P. \\ School of Science and Technology, \\ Plateau State Polytechnic, Barkin Ladi, Nigeria
}

\section{Doi:10.5901/ajis.2013.v2n12p45}

\section{Abstract}

A cross - sectional study of bovine, porcine and dog cysticercosis was carried out in Bukuru Plateau State Nigeria, in 2010 using Gyel Bukuru abattoir, Fwagul and Kuru trade centre slaughtering abattoir, as study areas. Two hundred and twenty-five samples were collected at random comprising of seventy-five samples each from cattle, dog and pig respectively, where twenty-five samples were taking for raw meat, cooked meat and feaces in relation to the sex of the animals examined. The overall prevalence rate of $28(12.44 \%)$ was recorded out of the total sample of 225. Raw meat records $10(4.44 \%)$, cooked meat record $7(3.11 \%)$ and feaces records $11(4.98 \%)$ infection rate. $X 2$ analysis show no significant difference in the prevalence rate of cysticercus in meat and cyst in feaces of the examined animals $(p>0.05)$. There was no record of infection in cattle, both in beef and feaces in different sexes of the cattle examined, sex specific incidence rate obtained in both studies did not differ significantly $(p>0.05)$. The female animal studied had the highest infection rate of 17(60.71\%). There was significant difference in tapeworms encountered with the meat and feaces examined $(p<0.05)$ Taenia solium had the highest infection rate of 14(6.22\%), Dipylidium caninum had 12(5.33\%) with the least infestatioin recorded in $T$. hydatigena $2(0.89 \%)$. Hence no record of $T$. saginata infection was encountered in the present study. However mixed infection was recorded in Dog with $T$. hydatigena \& D. caninum.

\section{Introduction}

Cysticercosis is caused by the larval stage of the tapeworm Taenia solium, Taenia saginata and Dipylidium caninum, clinical syndromes include neurocysticercosis (NCC) and extraneural cysticercosis. In endemic areas NCC is an important cause of adult-onset seizures (Montano et al, 2005). Cysticercosis caused by the larval stage of the worms (T.Solium, T. Saginata, Oand D.caninum) are highly important, but under-recognised parasitic zoonosis in many developing countries and particularly in Africa (Geerts et al, 1995). Cysticercosis is a frequent infection in Pigs, Dogs and humans in developing countries (Manuela et al, 2003).

Human taeniasis is mainly caused by two parasites which use man as definitive host Taenia solium and Taenia Saginata. The adult tape worms live in the small intestine. If eggs of the parasite that have been passed out in the faeces and are ingested by pigs ( $T$.Solium), cattle (T.Saginata) or Dog (Dipylidium caninum), they develop into the larval forms called cysticerci. These are frequently located in the muscle. Human contact taeniasis/ cysticercosis after ingesting viable cysticerci in raw or undercooked pork, beef or dog meat. The scolex within the cysticercus is freed, attached in the human small intestine and matures into the adult tapeworm within 10 weeks. When the tapeworm matures, microscopic eggs containing infective Onchosphere are passed in human faeces and ingested by pigs, cattle or dogs the intermediate host. The egg hatches in the 
intestinal tract and the Oncosphere is freed, migrates through the intestinal wall, and gains access via the circulatory system to the muscles, brain and other tissues of the host, where it transforms into the metacestode form or cysticercus. It has effect on human health economic losses due to the condemnation of heavily infected carcasses and the necessity to freeze or boil infected meat. Losses may also occur from restriction of exports (Murrel, 1991).Control of cysticercosis has been achieved in developed countries through improved hygiene, sanitation and properly maintained commercial piggeries.

However, in developing counties including Nigeria the disease is highly endemic in all areas where pigs, cattle and Dogs raising is practiced. Eating infected raw or undercooked pork, beef or dog meat can cause people to become infected with the adult tapeworm form of the parasite (taeniasis). If humans come into contact with infected human stool and accidentally ingest the eggs develop into the larval form of the tapeworm, which targets the muscles the eyes and most commonly the brain (Neurocysticercosis), manifesting as cysts. This may occur through direct contact with a tapeworm carrier's infested stool, by putting contaminated fingers in the mouth, or through ingestion of water or foods that have become contaminated with the infected faeces.

\section{Aim and Objectives of the Study}

i. The project is aimed at surveying for the presence of cysticercus (Bladder worm) in meat.

ii. To detect the cystic form of the larvae on faeces of the infected animals in the study area.

iii. To compare the rate of infection in relation to the sex of the study animals.

\section{Materials and Method}

The materials used for this project (research work) include:

Sample container, hand glove (Rubber), Laboratory coat, cover slip, sterile grease free glass slide, universal bottle, sterile Polythene bag, Nose mask, siever, Rubber Beaker, Applicator stick, stainless steel tray, compound Binocular microscope, fresh feaces of cow, pig $\&$ Dog, Fresh meat of cow, pig and dog, cooked meat of cow, pig and Dog, sterile scissors, sterile petri-dishes, maskin tape and bold pen.

Solutions used Saturated salt solution (SSS) Lime water $\left(\mathrm{Ca}(\mathrm{OH})_{2}\right)$ and Tap water.

Case study area :The case study area for this work was Bukuru and its Environs, which comprises of Bukuru Abbatoir (Gyel), Fwagul and Trade centre Kuru pig slaughtering Abbatoir.

Sample size: The total sample size was 225 , it is sub divided into the following:

i. Twenty five (25) pieces of fresh meat (Beef)

ii. Twenty five (25) pieces of fresh meat (Pork)

iii. Twenty five (25) pieces of fresh meat (Dog Meat)

iv. Twenty five (25) portion of fresh feaces of cow

V. Twenty five (25) portion of fresh feaces of Pig

vi. Twenty five (25) portion of fresh feaces of Dog

vii. Twenty five (25) pieces of cooked meat (Beef)

viii. Twenty five (25) pieces of cooked meat (pork)

ix. Twenty five (25) pieces of cooked Dog 0 (meat)

\subsection{Method of sample collection}

The method of sample collection employ for this project work (research) was the random sampling technique. The sample were collected at an interval of two (2) weeks at random five consecutive times, total of 50 (fifty) sample were collected each two weeks. In the last week 25 sample were collected. The sex of each study animal was also noted in the course of the sample collection. The samples were transported to the laboratory for analysis. 


\subsection{Techniques used}

Two techniques were employed here. Liming technique was to detect the presence of the larval form of the parasite (cysticercus) in the meat sample (both fresh and cooked meat) and floatation technique was employ to detect the presence of the cystic form of the parasite in the fresh feacal samples collected.

\subsubsection{Procedure i: Liming technique}

- Sterile Petri dish were labeled and placed on a stainless steel tray.

- Each samples were cut using sterile scissors and were placed on the petri dishes according to their label.

- Some few drops of lime water were apply on the piece of the meat contained in the petri dish.

- The set up was allowed to stand for 60 to 120 seconds

- And was observed for the presence of the larval form of the parasite (cysticercus)

- The results obtained is shown in chapter four of this research work.

\subsubsection{Procedure ii: Floatation technique}

- About $50 \mathrm{ml}$ solution of saturated salt solution (SSS) were added to a labeled universal container.

- About $1 \mathrm{~g}$ of fresh feacal sample was added to the solutions in the container.

- Applicator stick was used to mix the fresh feacal sample with the solution.

- $\quad$ The mixed sample was sieved into a beaker using siever.

- The universal container was washed with the applicator stick using a gentle flood tap water.

- The filtrate was decanted into the universal container and saturated salt solution was added to it until it was filled to the brim in a stainless steel tray.

- Clean grease free sterile glass slide was placed gently on the container trapping of air bubbles was avoided.

- The set ups was allowed to stand for 10-15 minute.

- The slide were removed carefully and covered with a cover slip and was examined using a compound Binocular microscope with $\mathrm{X} 10$ and $\mathrm{X} 40$ objective lens respectively.

- Same procedure was repeated to all the numbers of samples analyzed using the floatation method

\section{Results}

Table 1: Prevalence rate of cysticercus in meat (raw $\&$ cooked) and cyst in feaces of the examined animals

\begin{tabular}{|c|c|c|c|c|c|c|c|c|}
\hline $\begin{array}{l}\text { Animals } \\
\text { examined }\end{array}$ & $\begin{array}{c}\text { No. of samples } \\
\text { examined(meat and } \\
\text { feaces) }\end{array}$ & $\begin{array}{l}\text { No. of mea } \\
\text { examined }\end{array}$ & & $\begin{array}{l}\text { No. of } \\
\text { feaces } \\
\text { examined }\end{array}$ & $(\%)$ & $\begin{array}{l}\text { No. of meat } \\
\text { infected in } \\
(\%)\end{array}$ & & $\begin{array}{l}\text { No. of feaces } \\
\text { infected in } \\
(\%)\end{array}$ \\
\hline & & RM & CM & & Total & RM & $\mathrm{CM}$ & \\
\hline Cattle & 75 & $50(25$ & 25) & 25 & $0(0.00)$ & $0(0.00)$ & $0(0.00)$ & $0(0.00)$ \\
\hline Dog & 75 & $50(25$ & 25) & 25 & $14(18.67)$ & $5(6.67)$ & $3(4.00)$ & $6(8.00)$ \\
\hline Pig & 75 & $50(25$ & 25) & 25 & $14(18.67)$ & $5(6.67)$ & $4(5.33)$ & $5(6.67)$ \\
\hline Total & 225 & 150 & & 75 & $28(12.44)$ & $10(4.44)$ & $7(3.11)$ & $11(4.89)$ \\
\hline
\end{tabular}

Key RM= Raw Meat; $\mathrm{CM}=$ Cooked Meat.

$\mathrm{X}^{2}$ calculated value $\mathrm{X}^{2}$ Tabulated value 
$\mathrm{df}=4$ at $0.05 p$.

Table 2: Infection rate of the tapeworm (cysticercus \& cyst) in the different sexes of the examined animal

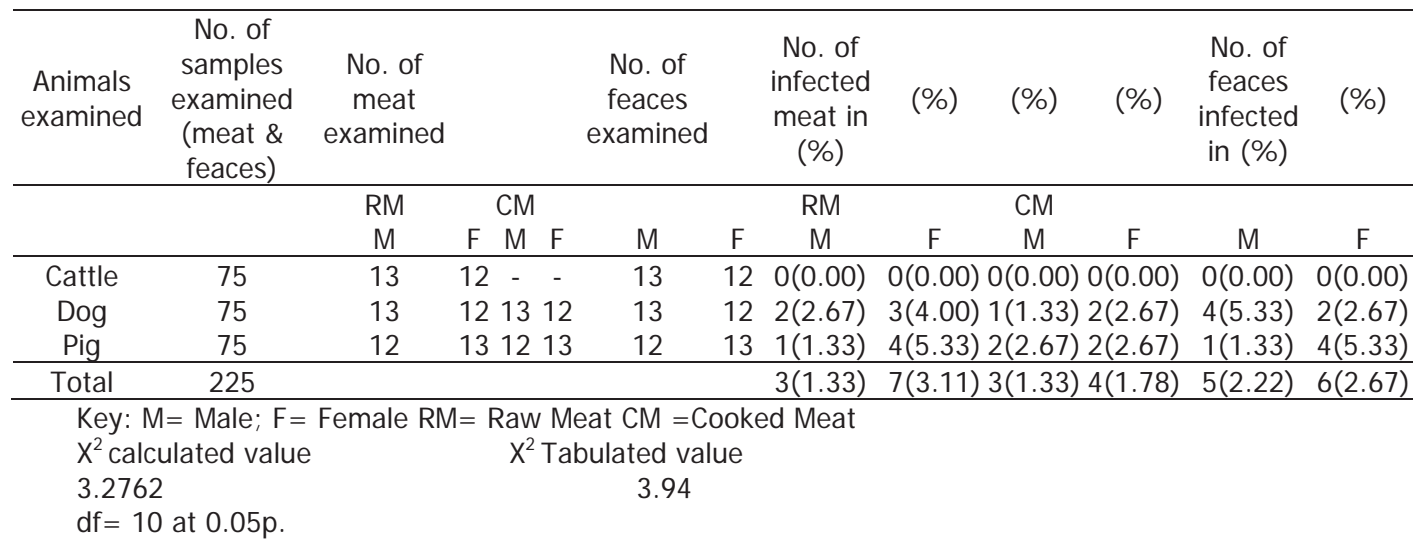

Table 3: Tapeworms (cysticercuc \& cyst) encountered and their Prevalence rate in the examined animals

\begin{tabular}{cccccccc}
\hline $\begin{array}{c}\text { Animals } \\
\text { examined }\end{array}$ & $\begin{array}{c}\text { No. of } \\
\text { samples } \\
\text { examined }\end{array}$ & $\begin{array}{c}\text { No. of meat } \\
\text { examined(RM\&CM) }\end{array}$ & $\begin{array}{c}\text { No. feacal } \\
\text { samples } \\
\text { examined(M\&F) }\end{array}$ & $\begin{array}{c}\text { Taenia } \\
\text { saginata } \\
(\%)\end{array}$ & $\begin{array}{c}\text { T. solium } \\
(\%)\end{array}$ & $\begin{array}{c}\text { T. } \\
\text { hydatigema } \\
(\%)\end{array}$ & $\begin{array}{c}\text { Dipylidium } \\
\text { caninum } \\
(\%)\end{array}$ \\
\hline Cattle & 75 & 50 & 25 & $0(0.00)$ & $0(0.00)$ & $0(0.00)$ & $0(0.00)$ \\
Dog & 75 & 50 & 25 & $0(0.00)$ & $0(0.00)$ & $2(2.67)$ & $12(16.00)$ \\
Pig & 75 & 50 & 25 & $0(0.00)$ & $14(18.67)$ & $0(0.00)$ & $0(0.00)$ \\
\hline Total & 225 & 150 & 75 & $0(0.00)$ & $14(6.22)$ & $2(0.89)$ & $12(5.33)$ \\
\hline$X^{2}$ Calculate value & \multicolumn{7}{c}{ X Tabulated value $^{2}$} \\
13.50 & \multicolumn{2}{c}{12.59} \\
df $=6$ at 0.05P.
\end{tabular}

Table I shows the prevalence rate of cysticercus in meat (raw $\&$ cooked) and cyst in feaces of the examined Animals. There was no record of any infection associated with cysticercus in cattle as well as cyst in feaces. Pigs and dogs recorded same infection rate of $5(6.67 \%)$ in raw meat while $4(5.33 \%)$ and $3(4.00 \%)$ in cooked meat repectively.

The feacal sample of dog and pigs showed infection as $6(8.0 \%)$ and $5(6.67 \%)$ respectively. This study reveals an overall prevalence rate of $28(12.44 \%)$ in the examined samples. However, $\mathrm{X}^{2}$ analysis indicates that there was no significant difference in the prevalence rate of cysticercus in meat and cyst in feaces of the examined animals ( $P>0.05)$.

Table II: Shows the infection rate of the tapeworm (cysticercus $\&$ cyst) in the different sexes of the examined animals. The raw meat of the female animals examined had the highest infection rate of $7(3.11 \%)$ with the least infection rate recorded in the raw and cooked meat of the male animals $3(1.33 \%)$ respectively. The cyst was more in the female feacal sample recording $6(2.67 \%)$. the raw meat (pork) from the female pig had the highest infection rate of $4(5.33 \%)$, followed by the female raw meat of Dog $3(4.00 \%)$, with least recorded in the male raw and cooked meat of Pigs and dogs, respectively.

The cysts of the parasite were more common in the male and female, dogs and pigs 4 $(5.33 \%)$ respectively. Hence, $X^{2}$ analysis reveals that there was no significant difference in the 
infection rate of the tapeworm in different sexes of the studied animals ( $P>0.05)$.

Table III: Shows the tapeworms encountered and their prevalence rate. There was no record of infection associated with cattle both in beef and feaces. Taenia solium had the highest rate of infection of $14(6.22 \%)$ followed by Dipylidium caninum $12(5.33 \%)$ with the least recorded in $T$. hydatigena $2(0.89 \%)$ respectively.

In Dogs, D. caninum had the highest rate of infection of $12(16.00 \%)$ and the least record of infection in $T$. hydatigena $2(2.67 \%), T$. Solium was the only tapeworm encountered in pigs with infection rate of $14(18.67 \%)$. However, $X^{2}$ analysis indicate that there was significant difference in tapeworm encountered in the examined animals $(P<0.05)$.

However, at the course of this research the following cyst of parasite were also encountered in the feaces of the examined animals:

Cattle: Oesophagastomum radiatum Mecistocirrus digitatus, Bunastomum phlebotomum, Paramphistomum cervi, Eimeria sp strongyla eggs, Toxocara vitulorum, Fasciola gigantica \& Trichuris globulosa

Dogs: Ancylostoma caninum, Necator sp, Isospora canis,

Pigs: Eimeria sp, Paragonimus westermonii, Necator sp, Oesophagostomum dentatum, Nnetastrongylus apri \& Ascaris lumbricoides.

\section{Discusions}

In the present study, no cysticercus or cyst of Taenia saginata was recorded in the meat and feaces of cattle examined, with prevalence rate of $75(0.0 \%)$. This result is in partial accordance to the report of Ofukwu et al, (2009) that recorded $0.7 \%$ in bovine (cattle) in Makurdi, North central Nigeria. This partial accordance may be attributed to local regulation to keep cattle restrain particularly the crises that restrict cattle rearing, latrines inside or outside household, awareness of personal hygiene and proper beef preparation, avoidance of ingestion of infected beef, rejection by the butchers of infected cattle and awareness of the population. Pigs had a prevalence rate of $9(32.14 \%)$ after routine meat (Pork) investigation as compared to that of Phiri, et al., (2006) in porcine Cysticercosis in Zambia village Pigs, that reported prevalence rate of 31 (47.7\%). However, a prevalence rate of $5(17.86 \%)$ was recorded for cyst in feaces of the examined pigs. This is inconsistent to the report of Allan et al., (1996) with 2.7\% in Guatemala. These variations may be due to dissimilarities in sample size, awareness of the population on the transmission dynamics of porcine cysticercosis. In the study, a prevalence rate of $8(28.57 \%)$ and $6(21.43 \%)$ was recorded for Dog meat with Dipylidium caninum and cyst in feaces of Dogs respectively, as against Echinococcus granulosus reported by Verastegui, et al., (2003) with a prevalence rate of $16(80.0 \%)$ in Peru, France. This variation may be due to differences in sample size, Dog management operations and environment.

Generally, Raw meat of the examined animals, had the highest infection rate than the cooked meat $(P>0.05)$ and the feaces having cyst than the meat examined.

In the present study, Bovine cysticercosis was not recorded in cattle, both in the meat and cyst of feaces in the males and females examined. However, Ofakwu, et al (2009) reported a higher proportion of infection with cysticercosis in meat and feaces of males $273(69.2 \%)$ and females $121(30.7 \%)$ cattles investigated respectively. Also, Allan et al, (1996) reported infection rate of porcine cysticercosis in meat (Pork) and feaces of males $33(2.1 \%)$ and females $59(3.3 \%)$ of pigs examined. Generally the females animals examined had the higher infection rate $17(60.71 \%$ ) as against the males with $11(39.29 \%)$. These variations may be due to differences in sample size and awareness or public health education on the transmission of taeniasis.

In this study, Taenia saginata was not encountered in cattle examined in both the meat and cyst in feaces respectively. T. hydatigena $2(2.67 \%)$ and D.caninum $12(16.0 \%)$ recorded in dogs examined and $T$. solium $14(18.67 \%)$ found in pigs examined.

Multiple infections were only recorded in dogs as against monoparasitism or no parasitism in 
pigs and cattle respectively. Generally pigs had the higher infection rate of $14(6.22 \%)$. Phiri et al., (2003) revealed an infection rate of $43(66.15 \%$ ) of Taenia solium in meat and cyst in feaces of pigs, also Ofukwu, et al., (2009) reported an incidence rate of $9.2 \%$ of Taenia saginata in cattle at Makurdi, North central Nigeria. These variations may be attributed to dissimilarities in sample size, public awareness on cysticercosis and environment.

\section{Conclusion}

Cysticercus is of public health importance as long as meat remain the source of protein to man. The common meat in the study area includes Dog meat, pork and beef. The meat should be properly cooked so as to kill the bladder worm. Hence with proper management of meat and meats product the bladder worm will be reduced drastically.

\section{Recommendations}

Further study should be carried out in different part of the state (local government areas) on the same incidence in other to compare the rate of infection in the entire state. Health Education should be carried out in other to minimize infection to both man and animals. Meat and meats products should be properly cooked and prepared, and the feaces of the animals be properly disposed.

\section{References}

Allan J.C; Velasquez-Tohom M.; Garcia-Noval J.; Torres-Alvarez R.; Yurrita P.; Fletes P.; De Mata F.; Sotode Alfaro,H. and Craig,P.S. (1996): Epidemiology of intestinal taeniasis in four rural Guatemalan Communities. Annal of Tropical Medicine and parasitology. 90:2:157-168.

Geerts S; Tsang V.C.W and Wilson M (1995): Cysticercosis in Africa. Parasitol Today.11:389.

Manuela,V.; Robert, H.; Hector, H.; Garcia; Armando, E.;Gonzalez; Yanina, A.; Cesar, J.; Isakra, T.; Cesar, M.; Gavida; Minlevine; Victo and Tsang (2003). Prevalence of antibodies to unique Teania solum oncosphere antigen in Teaniasis and human, porcine cysticercosis. The cysticercosis working group in Peru. Pub July No. 2003.

Montano SM; Villaran MV and Yiquimiche L.(2005): Neurocysticercosisi. Association Between seizures serelogy and brain CT in rural Peru. Neurology. 65:2:229- 234.

Murrell KD.(1991): Economic losses resulting from food-borne parasitic zoonoses.South-East Asian trop med pub health.22:377-81.

Ofukwu R.A; Akawuobu CA and Okwori Al. (2009): Epidemiology and public health Importance of bovine cysticercosis in Markurdi North-Central Nigeria. Tanzania Veterinary Journal. 26:1:3742.

Phiri, I.K; Dorny P; Gariel S; Willingham AL; Sikasunge C; Siziya S and Verestegui J.(2006): Assessment of routine inspection method for porcine cysticsrcosis in Zambian village pigs. Journal of Helminthology 8:69-72.

Verastegui M; Gonzalez A and Gilman RH.(2003): Experimental infection model for Taenia solium cysticercosis in swine. Vet Parasito/ 94:33-44. 